\title{
Tuberculosis in Selected Drug Abuse Treatment and Rehabilitation Centers (DATRCs) in Luzon, Philippines
}

\author{
Carl Abelardo T. Antonio, ${ }^{1,2}$ Jonathan P. Guevarra, ${ }^{3}$ Aubrey B. Lara, ${ }^{4}$ Eleanor C. Castillo, ${ }^{3}$ Lolita L. Cavinta, ${ }^{5,6}$ \\ Mikko Anthony L. Ting, ${ }^{4}$ Kyle Patrick Y. Eugenio, ${ }^{7}$ Kristine Joy L. Tomanan, ${ }^{4,8}$ Ma. Vilma V. Diez, ${ }^{9}$ \\ Anna Marie Celina G. Garfin, ${ }^{10}$ Manuel C. Panopio ${ }^{11,12}$ and Salvador Benjamin D. Vista ${ }^{13,14}$ \\ ${ }^{1}$ Department of Health Policy and Administration, College of Public Health, University of the Philippines Manila, Manila, Philippines \\ ${ }^{2}$ Department of Applied Social Sciences, The Hong Kong Polytechnic University, Kowloon, Hong Kong SAR \\ ${ }^{3}$ Department of Health Promotion and Education, College of Public Health, University of the Philippines Manila, Manila, Philippines \\ ${ }^{4}$ College of Public Health, University of the Philippines Manila, Manila, Philippines \\ ${ }^{5}$ Department of Medical Microbiology, College of Public Health, University of the Philippines Manila, Manila, Philippines \\ ${ }^{6}$ Institute of Herbal Medicine, National Institutes of Health, University of the Philippines Manila, Manila, Philippines \\ ${ }^{7}$ College of Medicine, University of the Philippines Manila, Manila, Philippines \\ ${ }^{8}$ Department of Community Development, College of Social Work and Community Development, University of the Philippines Diliman, Quezon City, Philippines \\ ${ }^{9}$ Dangerous Drug Abuse Prevention and Treatment Program, Department of Health, Manila, Philippines \\ ${ }^{10}$ National Tuberculosis Control Program, Department of Health, Manila, Philippines \\ ${ }^{11}$ Philippine College of Addiction Medicine, Quezon City, Philippines \\ ${ }^{12}$ Department of Health Treatment and Rehabilitation Center - Bicutan, Taguig City, Philippines \\ ${ }^{13}$ Group for Addiction Psychiatry of the Philippines, Pasig City, Philippines \\ ${ }^{14}$ Department of Psychiatry and Behavioral Medicine, College of Medicine and Philippine General Hospital, University of the Philippines Manila, Manila, Philippines
}

\begin{abstract}
Background and Objectives. Tuberculosis (TB) continues to be a public health concern in the Philippines. Vulnerable populations in congregate settings such as drug abuse treatment and rehabilitation centers (DATRCs) have higher risks of TB transmission and infection. With the Duterte administration's intensified campaign against illegal drugs, government-retained DATRCs are filled to capacity. There is an identified need to profile drug users and dependents living in DATRCs. Furthermore, national guidelines for TB management specific to this population is absent. A study was conducted to determine the profile of admitted clients diagnosed with TB, TB prevalence, treatment outcomes and choice of TB diagnostic modalities in six (6) Luzon-based DATRCs from 2013-2015.
\end{abstract}

Methods. All medical records of drug users admitted in this period were reviewed. Information on the total patient census was sought from DATRC heads and used to compute for prevalence.

Results. A total of 347 records were obtained. Overall TB prevalence in the study sites was 7,216 per 100,000 population. The typical individual diagnosed with TB in a DATRC was male, with a mean age of 35 years, with at least high school education, and unemployed. Weight loss and fatigue were the most common symptoms reported. The majority (79.83\%) completed TB treatment in the DATRCs. Sputum microscopy and chest x-ray were both used for TB diagnosis in $92.80 \%$ (322) of the cases.

Conclusion. The high burden of TB in Luzon-based, government-retained DATRCs is alarming and underscore the critical need for standards and guidelines in the National Tuberculosis Control Program addressing the unique context of these facilities.

Key Words: tuberculosis, epidemiology, prevalence, substance abuse treatment centers, drug rehabilitation centers, Philippines

\section{INTRODUCTION}

Corresponding author: Carl Abelardo T. Antonio, MD, MPH Department of Health Policy and Administration College of Public Health, University of the Philippines Manila 625 Pedro Gil Street, Ermita, Manila 1000, Philippines Email: ctantonio@up.edu.ph
Tuberculosis (TB) remains a public health concern in the Philippines and continues to be among the ten leading causes of morbidity and mortality. ${ }^{1,2}$ Health-related Sustainable Development Goals (SDGs) and World Health Organization's (WHO) End TB Strategy call for stronger commitment 
and more extensive efforts in enhancing TB prevention and control including among vulnerable populations in congregate settings such as prisons and rehabilitation centers, which have higher risks of TB transmission. ${ }^{3,4}$

With the Duterte administration's intensified antiillegal drug campaign, government-retained drug abuse treatment and rehabilitation centers (DATRCs) are filled to capacity. ${ }^{5}$ Relatedly, there is an identified need to profile groups vulnerable to $\mathrm{TB}$, such as drug users and dependents living in DATRCs, so that appropriate intervention can be developed for their needs and unique context.

Alongside the increased risk for developing TB among drug users, and the absence of national guidelines on the management of TB among this vulnerable population, we conducted a study in 2017 to inform and improve existing national and institutional policies, programs and practices related to $\mathrm{TB}$ in case finding and case holding among drug users and dependents in treatment and rehabilitation centers in the Philippines.

This report focuses on the study's findings regarding demographic and clinical characteristics and outcomes among admitted clients diagnosed with $\mathrm{TB}$ in selected Luzon-based, government-retained DATRCs from the period of 2013-2015.

\section{METHODS}

A descriptive, cross-sectional study was conducted from April to October 2017 in six selected Department of Health (DOH)-retained DATRCs in Luzon. All medical records of drug users admitted between 2013 to 2015 in these facilities were reviewed. Data abstraction from available records were done using a standardized form developed by the research team. Information on the total patient census for the calendar years 2013 to 2015 was sought from DATRC heads, which was used as the denominator in the computation of prevalence. Actual names of the six facilities were concealed and replaced with codes (i.e. DATRC A, B, C, D, E, F) for confidentiality. One personnel from each participating facility was requested to abstract the needed data from medical records.

Facility data were analyzed using univariate statistics (proportion, means, standard deviation) through STATA (Stata Statistical Software: Release 14; College Station, TX:
StataCorp LP, 2015). In consideration of a large number of cases contributed by DATRC C (89.34\%) in comparison to the other facilities, data from DATRC $\mathrm{C}$ are presented separately. The prevalence of TB in DATRCs was obtained by dividing the number of reported TB cases in all DATRCs by the total number of persons admitted in DATRCs.

The research proposal was reviewed by an internal project expert panel, as well as by an independent panel of referees selected by the sponsoring organization. Ethics approval before the conduct of data collection was obtained from the University of the Philippines Manila Research Ethics Board and the WHO Western Pacific Regional Office Ethics Review Committee.

\section{RESULTS}

\section{Number of records obtained and total patient census}

A total of 347 abstraction forms from six participating government-retained DATRCs in Luzon were retrieved. The number of records obtained per facility is shown in Table 1 , with DATRC C having both the highest number of clients diagnosed with TB and the total census for the period of 2013-2015.

The overall prevalence of $\mathrm{TB}$ in the study sites was calculated as 7,216 per 100,000 population. Table 1 also shows TB prevalence per facility, with DATRC C having the most number of clients diagnosed with TB during 2013-2015, at 310 out of 3,407. Considering only the five other DATRCs, the prevalence of TB is reduced by a third $(2,639$ per 100,000$)$.

\section{The overall profile of clients diagnosed with TB}

In general, the typical person diagnosed with TB was male with a mean age of 35 years, with at least high school education, and unemployed before confinement in the facility. Roughly seven percent (7.2\%) of the TB patients have a prior history of TB while $3.46 \%$ have a family history of TB. As for symptomatology and diagnosis, $32.85 \%$ exhibited more than one $(>1)$ symptom with weight loss and easy fatigability as the most common among those who indicated their symptom presentation. Tables 2 and 3 summarize the demographic and clinical characteristics of $347 \mathrm{~TB}$ cases identified in the six participating facilities.

Table 1. Prevalence of TB in selected drug abuse treatment and rehabilitation centers (DATRCs), Luzon, Philippines, 2013-2015

\begin{tabular}{crrrrr}
\hline Facility & \multicolumn{1}{c}{ Records retrieved (diagnosed TB) } & \multicolumn{1}{c}{ Total census (2013-2015) } & Prevalence (per 100,000) \\
DATRC A & 3 & $0.86 \%$ & 211 & $4.39 \%$ & 1,422 \\
DATRC B & 6 & $1.73 \%$ & 312 & $6.49 \%$ & 1,923 \\
DATRC C & 310 & $89.34 \%$ & 3,407 & $70.85 \%$ & 9,099 \\
DATRC D & 11 & $3.17 \%$ & 404 & $8.40 \%$ & 2,723 \\
DATRC E & 11 & $3.17 \%$ & 211 & $4.39 \%$ & 5,213 \\
DATRC F & 6 & $1.73 \%$ & 264 & $5.49 \%$ & 2,273 \\
\hline Total & \multirow{2}{*}{347} & & \multirow{2}{*}{4,809} & All DATRCs \\
\hline
\end{tabular}


Table 2. Demographic characteristics of clients diagnosed with TB in selected DATRCs, Luzon, Philippines, 2013-2015

\begin{tabular}{|c|c|c|c|}
\hline Parameter & DATRC C only $(\mathrm{N}=310)$ & Five other DATRCs $(\mathrm{N}=37)$ & All Sites $(\mathbf{N}=347)$ \\
\hline $\begin{array}{l}\text { Age group } \\
\quad \leq 19 \\
20-29 \\
30-39 \\
40-49 \\
50-59 \\
\geq 60 \\
\text { No answer }\end{array}$ & $\begin{array}{r}14(4.52 \%) \\
77(24.84 \%) \\
120(38.71 \%) \\
72(23.23 \%) \\
22(7.10 \%) \\
4(1.29 \%) \\
1(0.32 \%) \\
\end{array}$ & $\begin{array}{r}1(2.70 \%) \\
10(27.03 \%) \\
19(51.35 \%) \\
7(18.92 \%) \\
- \\
- \\
-\end{array}$ & $\begin{array}{r}15(4.32 \%) \\
87(25.07 \%) \\
139(40.06 \%) \\
79(22.77 \%) \\
22(6.34 \%) \\
4(1.15 \%) \\
1(0.29 \%) \\
\end{array}$ \\
\hline $\begin{array}{l}\text { Sex } \\
\text { Male } \\
\text { Female } \\
\text { No answer }\end{array}$ & $\begin{array}{r}289(93.23 \%) \\
20(6.45 \%) \\
1(0.32 \%) \\
\end{array}$ & $\begin{array}{r}36(97.30 \%) \\
1(2.70 \%) \\
- \\
\end{array}$ & $\begin{array}{r}325(93.66 \%) \\
21(6.05 \%) \\
1(0.29 \%) \\
\end{array}$ \\
\hline $\begin{array}{l}\text { Educational Attainment } \\
\text { Elementary Graduate } \\
\text { Elementary Undergraduate } \\
\text { High School Graduate } \\
\text { High School Undergraduate } \\
\text { College - Bachelor's Degree Graduate } \\
\text { College - Bachelor's Degree Undergraduate } \\
\text { Vocational Graduate } \\
\text { Not Indicated }\end{array}$ & $\begin{array}{r}19(6.13 \%) \\
28(9.03 \%) \\
79(25.48 \%) \\
94(30.32 \%) \\
23(7.42 \%) \\
48(15.48 \%) \\
10(3.32 \%) \\
9(2.90 \%)\end{array}$ & $\begin{array}{r}- \\
3(8.11 \%) \\
7(18.92 \%) \\
3(8.11 \%) \\
6(16.22 \%) \\
6(16.22 \%) \\
1(2.70 \%) \\
9(24.32 \%)\end{array}$ & $\begin{array}{r}19(5.48 \%) \\
31(8.93 \%) \\
86(24.78 \%) \\
99(28.53 \%) \\
29(8.36 \%) \\
54(15.56 \%) \\
11(3.17 \%) \\
18(5.19 \%)\end{array}$ \\
\hline $\begin{array}{l}\text { Employment Status } \\
\text { Employed, Government Full-time } \\
\text { Employed, Government Part-time } \\
\text { Employed, Private Full-time } \\
\text { Employed, Private Part-time } \\
\text { Self-Employed } \\
\text { Unemployed } \\
\text { OFW } \\
\text { Not Indicated } \\
\text { No Answer }\end{array}$ & $\begin{array}{r}6(1.94 \%) \\
1(0.32 \%) \\
9(2.90 \%) \\
18(5.81 \%) \\
46(14.84 \%) \\
221(71.29 \%) \\
1(0.32 \%) \\
6(1.94 \%) \\
2(0.65 \%)\end{array}$ & $\begin{array}{r}1(2.70 \%) \\
- \\
4(10.81 \%) \\
1(2.70 \%) \\
6(16.22 \%) \\
15(40.54 \%) \\
- \\
6(16.22 \%) \\
4(10.81 \%)\end{array}$ & $\begin{array}{r}7(2.02 \%) \\
1(0.29 \%) \\
13(3.75 \%) \\
19(5.48 \%) \\
52(14.99 \%) \\
236(68.01 \%) \\
1(0.29 \%) \\
12(3.46 \%) \\
6(1.73 \%)\end{array}$ \\
\hline
\end{tabular}

Notes: 'No Answer' means that data collectors were unable to fill out the answer for that specific category in the abstraction form while 'Not Indicated' signifies the DATRC's lack of record for the particular data.

The mean age of persons diagnosed with TB is 34.69 years old (standard deviation: 10.02 years), with the youngest being 10 years old and the oldest 67 years old coming from DATRC C. The highest number of TB cases belong to the age group of 30-39 years at 139 cases, which comprise the majority of the cases in the study.

Around ninety-four percent (93.66\%) of the cases are males and six percent (6.05\%) are female. Males outnumber females by a ratio of 15.5:1. The bulk of male patients come from DATRC C (289 out of 325, Table 2).

\section{Educational attainment}

Medical records showed $28.53 \%$ of clients diagnosed with TB were high school undergraduates, $24.78 \%$ finished high school, $16 \%$ were college undergraduates while $8.36 \%$ graduated from college (Table 2). Of the total cases, $68.01 \%$ were unemployed before their admission to DATRCs. Patients from DATRC C comprise the majority (221 out of 236) who indicated being unemployed.

\section{Clinical characteristics of clients diagnosed with TB}

As shown in Table 3, the majority of identified patients have no prior history of TB (302 or $87.03 \%$ ). Only $7.2 \%$ of
TB patients have a prior history of TB while $3.46 \%$ have a family history of TB.

Almost half of the patients (160 or 46.11\%) specified they did not have any history of TB in the family. On the other hand, it was also noted that $48.41 \%$ of the records reviewed (168) did not indicate the patients' family history of $\mathrm{TB}$, which meant that DATRCs were not able to include this information in patient records.

As for symptomatology and diagnosis, $32.85 \%$ exhibited more than one symptom with weight loss and easy fatigability as the most common among those who indicated their symptom presentation.

\section{Modalities used in TB diagnosis}

The $92.80 \%$ of the cases (322) were diagnosed based on results of sputum microscopy (with or without chest $\mathrm{x}$-ray), with 302 cases coming from DATRC C. Only 2 or $0.58 \%$ used direct sputum smear microscopy (DSSM) only for TB diagnosis, while 17 or $4.90 \%$ used chest $\mathrm{x}$-ray only. No DATRC specified conducting diagnostic procedures for extrapulmonary TB (EPTB). 
Table 3. Clinical characteristics of clients diagnosed with TB in selected DATRCs, Luzon, Philippines, 2013-2015

\begin{tabular}{|c|c|c|c|}
\hline Parameter & DATRC C only $(\mathrm{N}=310)$ & Five other DATRCs $(\mathrm{N}=37)$ & All Sites ( $\mathbf{N}=347)$ \\
\hline $\begin{array}{l}\text { Prior history of TB } \\
\text { Diagnosed with TB } \\
\text { Diagnosed with TB, Treated for TB } \\
\text { Treated for TB } \\
\text { No prior history of TB } \\
\text { Not Indicated } \\
\text { No Answer }\end{array}$ & $\begin{array}{r}4(1.29 \%) \\
2(0.65 \%) \\
3(0.97 \%) \\
284(91.61 \%) \\
2(0.65 \%) \\
15(4.84 \%)\end{array}$ & $\begin{array}{r}12(32.43 \%) \\
2(5.41 \%) \\
2(5.41 \%) \\
18(48.65 \%) \\
- \\
3(8.11 \%)\end{array}$ & $\begin{array}{r}16(4.61 \%) \\
4(1.15 \%) \\
5(1.44 \%) \\
302(87.03 \%) \\
2(0.58 \%) \\
18(5.19 \%)\end{array}$ \\
\hline $\begin{array}{l}\text { Family history of TB } \\
\text { Yes } \\
\text { No } \\
\text { Not Indicated } \\
\text { No Answer }\end{array}$ & $\begin{array}{r}12(3.87 \%) \\
126(40.65 \%) \\
166(53.55 \%) \\
6(1.94 \%)\end{array}$ & $\begin{array}{r}- \\
34(91.89 \%) \\
2(5.41 \%) \\
1(2.70 \%)\end{array}$ & $\begin{array}{r}12(3.46 \%) \\
160(46.11 \%) \\
168(48.41 \%) \\
7(2.02 \%)\end{array}$ \\
\hline $\begin{array}{l}\text { Symptoms of TB prior to Diagnosis } \\
\text { Cough of at least } 2 \text { weeks } \\
\text { Significant weight loss } \\
\text { Chest/back pain } \\
\text { Easy fatigability } \\
\text { Night sweats } \\
\text { Difficulty of breathing } \\
\text { Not Indicated } \\
\text { No Answer } \\
\text { Other } \\
\text { More than one }\end{array}$ & $\begin{array}{r}1(0.32 \%) \\
59(19.03 \%) \\
1(0.32 \%) \\
3(0.97 \%) \\
- \\
- \\
117(37.74 \%) \\
34(10.97 \%) \\
- \\
95(30.65 \%)\end{array}$ & $\begin{array}{r}2(5.41 \%) \\
- \\
- \\
- \\
1(2.70 \%) \\
1(2.70 \%) \\
11(29.73 \%) \\
1(2.70 \%) \\
2(5.41 \%) \\
19(51.35 \%)\end{array}$ & $\begin{array}{r}3(0.86 \%) \\
59(17.00 \%) \\
1(0.29 \%) \\
3(0.86 \%) \\
1(0.29 \%) \\
1(0.29 \%) \\
128(36.89 \%) \\
35(10.09 \%) \\
2(0.59 \%) \\
114(32.85 \%)\end{array}$ \\
\hline $\begin{array}{l}\text { Diagnostic Examination } \\
\text { Chest x-ray only } \\
\text { Sputum microscopy only } \\
\text { Sputum microscopy, Chest x-ray } \\
\text { No answer } \\
\end{array}$ & $\begin{array}{r}2(0.65 \%) \\
2(0.65 \%) \\
302(97.42 \%) \\
4(1.29 \%) \\
\end{array}$ & $\begin{array}{r}15(40.54 \%) \\
- \\
20(54.05 \%) \\
2(5.41 \%) \\
\end{array}$ & $\begin{array}{r}17(4.90 \%) \\
2(0.58 \%) \\
322(92.80 \%) \\
6(1.73 \%) \\
\end{array}$ \\
\hline $\begin{array}{l}\text { Treatment Outcome } \\
\text { Cured (bacteriologic confirmation) } \\
\text { Completed treatment (clinical confirmation) } \\
\text { Failed } \\
\text { Died } \\
\text { Discontinued treatment } \\
\text { Outcome unknown } \\
\text { No Answer }\end{array}$ & $\begin{array}{r}27(8.71 \%) \\
247(79.68 \%) \\
1(0.32 \%) \\
2(0.65 \%) \\
6(1.94 \%) \\
22(7.10 \%) \\
5(1.61 \%)\end{array}$ & $\begin{array}{r}- \\
30(81.08 \%) \\
1(2.70 \%) \\
- \\
- \\
6(16.22 \%) \\
-\end{array}$ & $\begin{array}{r}27(7.78 \%) \\
277(79.38 \%) \\
2(0.58 \%) \\
2(0.58 \%) \\
6(1.73 \%) \\
28(8.07 \%) \\
5(1.44 \%)\end{array}$ \\
\hline
\end{tabular}

Notes: 1. 'No Answer' means that data collectors were unable to fill out the answer for that specific category in the abstraction form while 'Not Indicated' signifies the DATRC's lack of record for the particular data. 2. For TB symptoms, no observations were reported for fever and hemoptysis. 3. For purposes of the study, we used the treatment outcome categories as used by the NTP, and as reflected in the medical record.

\section{Reported treatment outcomes}

Out of 347 cases on record, 277 or $79.83 \%$ of patients in DATRCs completed TB treatment. The majority of these patients came from DATRC C, at 247 out of 277 cases, while the other 30 came from the remaining five facilities. Overall, $27(7.78 \%)$ were classified as cured while $28(8.07 \%)$ had unknown outcomes. Six patients (1.73\%) had discontinued treatment, while two died and two had treatment failure. Five cases had "No Answer" as the category which meant that the required information was not available at the time of data collection.

\section{DISCUSSION}

In general, the results of the study revealed there is a high burden of TB in Luzon-based, government-retained DATRCs, at an overall prevalence of 7,216 per 100,000 (or 2,630 per 100,000 if only the five other DATRCs will be considered). The typical individual diagnosed with TB was male, with a mean age of 35 years, reached high school, and unemployed before admission. Weight loss and easy fatigability were the most common symptoms reported. Sputum microscopy and chest x-ray were both used for TB diagnosis in $92.80 \%$ (322) of the cases and the majority (79.83\%) completed TB treatment in the DATRCs.

The TB prevalence in DATRCs is substantially higher than the country prevalence estimated by Department of Health in the 2016 National Tuberculosis Prevalence Survey (1,159 bacteriologically confirmed and 434 smearpositive PTB per 100,000 population $)^{6}$, but is within the range reported for prisons, i.e., 2015 estimates done by the World Health Organization (4,500 per 100,000 in detention facilities) ${ }^{7}$ and Borja et al in 2011 (2,200 per $100,000$ population $)^{8}$.

To date, the current study is the first to report the prevalence of TB in drug abuse treatment and rehabilitation 
centers in the country. However, this was limited to a small subset of purposively selected government facilities in Luzon, which may preclude generalization to other facilities including the private sector. Nevertheless, the validation conducted with stakeholders points to the high probability that the team has exhaustively gathered data from the study sites, with little difference in experiences of other facilities not included from the study. Dependence or drug abuse significantly weakens the body's immunity and resistance which, together with environmental and behavioral factors of drug users, makes these particular groups of clients highly vulnerable to $\mathrm{TB}$ infection. ${ }^{9-13}$ As such, the high burden of disease in this setting is alarming and warrants an improvement in the current implementation of the National TB Control Program (NTP).

Although there are provisions under the 2014 NTP Manual of Procedures on congregate settings, specifications are only indicated for jails/prisons, which operate differently from DATRCs. ${ }^{14}$ Jails or prisons are managed by the Bureau of Jail Management and Penology (BJMP), an attached agency of the Department of Interior and Local Government (DILG), while the participating DATRCs are managed by the government through the Department of Health (i.e. DOH-retained). Based on the discussions conducted with health personnel in study sites, fund allocation for TB treatment in DATRCs and the existence of a functioning external referral system have been recognized to affect the practice and performance of these facilities.

Furthermore, as gleaned from the records reviewed and considering the current state of DATRCs (i.e. overcapacity due to intensified anti-drug campaign by the government), variations in the use of TB diagnostics across participating DATRCs underscore the crucial need for standards addressing the unique context of these facilities. The DATRCs in the study still use a chest $\mathrm{x}$-ray as the main modality of TB diagnosis, with only less than $1 \%$ using direct sputum smear microscopy only, the gold standard for diagnosis of TB. When utilized together, discussions with DATRC health personnel revealed that DSSM is used as a confirmatory test only when the $\mathrm{x}$-ray result is positive. No DATRC was noted to include the use of GeneXpert as a diagnostic tool on record, while according to interviews this was used in actual practice for five DATRCs through partner Directly Observed Treatment, Short-course (TBDOTS) facilities such as rural health units (RHUs). In addition, none of the DATRCs conducted diagnostic procedures for extrapulmonary TB (EPTB), which may cause these facilities to miss cases that can be captured using these methods.

On the other hand, in terms of treatment outcomes, the DATRCs show a relatively high treatment completion rate of approximately $80 \%$ but only around $8 \%$ with cured outcomes. The patient discharge may account for the low percentage reported as cured in the facilities and the aftercare program by the DATRC might not have prioritized the follow-up after TB treatment completion. Nevertheless, the DATRC aftercare program presents an opportunity for follow-up and ensuring completion of TB treatment for patients that must be taken advantage of by the NTP. A study by Zenner and colleagues demonstrated treatment completion rates as high as 9\% among illegal drug users whose screening and follow-up was embedded in a local TB clinic. ${ }^{15}$

Finally, the findings of this report should be cautiously interpreted due to the inherent limitations of the study. The team relied on medical records and did not have any mechanism to confirm the diagnosis declared in these records. It is also possible that the team may have missed some cases considering the variance of diagnostic modalities between DATRCs. Also, the team did not extensively analyze the patient-level data gathered in the study and was limited only to the description of the patient profile and analysis of clients diagnosed with TB. A nationwide TB prevalence survey among drug dependents and inclusion of private sector facilities as study sites are recommended to validate the results.

\section{CONCLUSION}

Drug users and dependents are highly vulnerable to TB infection and require special management. The high burden of TB in congregate settings such as drug abuse treatment and rehabilitation centers show that the present set-up cannot adequately provide quality care. Therefore, there is an urgent need to enhance existing standards and guidelines of the National TB Control Program addressing the unique context of these facilities in parallel with the conduct of training for DATRC staff on the latest version of the NTP Manual of Procedures.

\section{Acknowledgments}

Dr. Nina G. Gloriani (College of Public Health, University of the Philippines Manila) guided us throughout the whole research process for this project. Ms. Jillian T. Rausa (School of Public Health, Boston University) participated in the collection and preliminary analysis of part of the data used for this study. Ms. Kim L. Cochon (Department of Statistics, The Chinese University of Hong Kong) provided comments on the reporting of the method and result of statistical analysis. Ms. Glenda Gonzales (Division of Communicable Diseases, World Health Organization Regional Office for the Western Pacific, Manila, Philippines) and Ms. Rosario P. Vacal (University of the Philippines College of Public Health Foundation, Inc.) provided administrative support in the implementation of the project.

\section{Statement of Authorship}

CTA - conceptualization and design, data collection, data analysis, report writing, approval of final version submitted. 
JPG, LLC, ECC - design, data collection, data analysis, report writing, approval of final version submitted.

ABL, MLT - data collection, data analysis, report writing, approval of final version submitted.

All other authors - data analysis, report writing, approval of final version submitted.

\section{Author Disclosure}

Dr. Antonio received professional fees from Johnson \& Johnson (Philippines), Inc. Dr. Diez was program manager with the Department of Health overseeing DATRCs at the time of the study. Dr. Garfin is program manager with the Department of Health overseeing implementation of the tuberculosis control program. All other authors declare no conflict of interest.

\section{Funding Source}

This study was funded through the 2016-2017 cycle of the Joint World Health Organization Western Pacific Region (WPR) and Special Programme for Research and Training in Tropical Diseases (TDR) Small Grants Scheme for implementation research in infectious diseases of poverty (Contract No. 201590488).

\section{REFERENCES}

1. Department of Health. Morbidity [Internet]. Department of Health, Manila, Philippines. June 14, 2016 [cited 2017 Aug 31]. Available from: http://www.doh.gov.ph/morbidity

2. Department of Health. Mortality [Internet]. Department of Health, Manila, Philippines. June 3, 2016 [cited 2017 Aug 31]. Available from: http://www.doh.gov.ph/mortality

3. United Nations. Sustainable Development Goals [Internet]. United Nations, New York, n.d. [cited 2017 Sep 2]. Available from: http:// www.un.org/sustainabledevelopment/sustainable-development-goals/.

4. World Health Organization. WHO End TB Strategy [Internet]. Geneva, Switzerland: WHO Document Production Services. 2015 [cited 2017 Nov 5]. Available from: http://www.who.int/tb/post2015_ TBstrategy.pdf?ua $=1$
5. Maretti A. Prisons and rehab overcrowding in the Philippines [Internet]. Aljazeera. December 14, 2016 [cited 2017 Nov 5]. Available from: https://www.aljazeera.com/indepth/inpictures/2016/12/prisonsrehab-overcrowding-philippines-161207091046623.html

6. National Tuberculosis Prevalence Survey 2016 [Internet]. [cited 2017 Nov 15]. Available from: http://www.philcat.org/PDFFiles/ 2.NTPSPhilCAT_17Aug2017_Dr.\%20Lansang.pdf

7. International Committee of the Red Cross. Philippines: Intensifying detection of tuberculosis in jails and prisons [Internet]. 2016 [cited 2017 Aug 17]. Available from: https://www.icrc.org/en/document/ philippines-intensifying-detection-tuberculosis-jails-and-prisons

8. Borja MP, Mortera LL, Palasi WA, Benedicto JP, Cadena EV (Philippine Tuberculosis Society, Inc.). Prevalence of bacteriologically confirmed pulmonary tuberculosis among prisoners and jail officers in selected prisons in the Philippines. Final report. Taguig City: Philippine Council for Health Research and Development; 2011.

9. Durante AJ, Selwyn PA, O'Connor PG. Risk factors for and knowledge of Mycobacterium tuberculosis infection among drug users in substance abuse treatment. Addiction. 1998 Sep;93(9):1393-401. doi: 10.1046/j.1360-0443.1998.939139310.x.

10. Salomon N, Perlman DC, Friedmann P, Perkins MP, Ziluck V, Jarlais DC, et al. Knowledge of tuberculosis among drug users. Relationship to return rates for tuberculosis screening at a syringe exchange. J Subst Abuse Treat. 1999 Apr;16(3):229-35. doi: 10.1016/s07405472(98)00033-6.

11. Story A, Murad S, Roberts W, Verheyen M, Hayward AC; London Tuberculosis Nurses Network. Tuberculosis in London: the importance of homelessness, problem drug use and prison. Thorax. 2007 Aug;62(8):667-71. doi: 10.1136/thx.2006.065409.

12. Deiss RG, Rodwell TC, Garfein RS. Tuberculosis and illicit drug use: review and update. Clin Infect Dis. 2009 Jan;48(1):72-82. doi: $10.1086 / 594126$.

13. Deponti GN, Silva DR, Coelho AC, Muller AM, Dalcin Pde T. Delayed diagnosis and associated factors among new pulmonary tuberculosis patients diagnosed at the emergency department of a tertiary care hospital in Porto Alegre, South Brazil: a prospective patient recruitment study. BMC Infect Dis. 2013 Nov;13:538. doi: 10.1186/1471-2334-13-538.

14. Department of Health. Manual of Procedures of the National Tuberculosis Control Program, 5th ed. Manila, Philippines; 2014.

15. Zenner D, Southern J, van Hest R, Devries G, Stagg HR, Antoine $\mathrm{D}$, et al. Active case finding for tuberculosis among high-risk groups in low-incidence countries. Int J Tuberc Lung Dis. 2013 May;17(5): 573-82. doi:10.5588/ijtld.12.0920 